\title{
Evaluation of possibilities and risks in keeping bitcoins in the EU accounting records
}

\author{
Olga Regnerova $^{1^{*}, \text { and Jitka Siskova }}{ }^{2}$, \\ ${ }^{1,2}$ Czech University of Life Sciences Prague, Faculty of Economics and Management, Department of \\ Trade and Finances, Prague 6 - Suchdol, Czech Republic
}

\begin{abstract}
Research background: Cryptocurrencies are a specific form of currency that has emerged with the rise of globalization and the Internet. At present, there are still no necessary guidelines to enable bitcoin to be accounted for uniformly, not even within the framework of the international accounting standards IFRS.

Purpose of the article: That is to evaluate the possibilities of correct procedure in accounting for bitcoin according to applicable accounting regulations with identification of deficiencies and risks and overall impact on profit and loss statements and tax issues in reporting bitcoin, especially in income taxes and VAT.

Methods: The evaluation will be performed using model examples that focus on the use of bitcoin in business. Four model examples: 1. bitcoin as a means of payment, 2. bitcoin extraction, 3. bitcoin speculation, 4. evaluation of bitcoin billing when paying salaries. For individual variants, income tax will be calculated according to valid regulations and any difference will be compared. Based on the synthesis of the obtained results of model examples, the reporting of bitcoin according to Czech accounting standards will be evaluated with subsequent recommendations for accounting entities and pointing out possible risks for reporting.

Findings \& Value added: If an entity wishes to use bitcoin in the course of its business, it may be advised to create appropriate analytical accounts or off-balance sheet records. This issue should be discussed and addressed in the legislation. This is a global issue, so it is necessary to pay sufficient attention to the uniform approach in accounting.
\end{abstract}

Keywords: bitcoin; accounting; accounting standards; taxes

JEL Classification: $M 41 ; M 48 ; F 65$

\footnotetext{
*Corresponding author: oregnerova@pef.czu.cz
} 


\section{Introduction}

Cryptocurrencies are a specific form of currency that has emerged with the rise of the Internet. Such currencies use cryptographic encryption to confirm payments. They are accepted as a form of payment, but officially do not meet the definition of money.

Stroukal and Skalicky (2018) describe bitcoin as: "A decentralized P2P network on the Internet, managing the history of payment transactions between their nodes. The basic unit of the transaction is bitcoin. The number of units of this "cryptocurrency" is limited and new ones are created by the mining process.

The European Banking Authority (EBA) understands virtual currencies as a digital form of value that is not issued by a central bank or public authority or linked to a currency with forced circulation, but recognized by natural or legal persons as currency, and which can be transferred, deposited or traded by electronic means (European Parliament, 2016).

Cryptocurrencies such as Bitcoin, SETL coin, Ether, Solar Coin, or Liberty Reserve exist since 2009. Because of their decentralized control, they are often considered a threat or alternative to the conventional centralized banking system (Dierksmeier and Seele, 2018). Crypto-coins (CCs) like Bitcoin are digitally encrypted tokens traded in peer-to-peer networks whose money laundering potential has attracted the attention of regulators, firms and the wider public worldwide (Campbell-Verduyn, 2018). Any online transaction that involves digital money is a bit of a challenge these days with the rising threats of hackers trying to steal bank details posted online. This leads to the invention of various kinds of crypto-currency, Bitcoin being one of them (Niranjanamurthy et al., 2019).

Creative accounting is a very widespread concept that has led to the bad image of accountants and financiers in the financial and accounting world (Blazek et al., 2020). Financial risk is often perceived as the risk that a company may default on its debt payments (Valaskova et al., 2018). Due to the lack of EU legislation on cryptocurrencies, it is not easy to determine their correct accounting. For this reason, the issue of cryptocurrency reporting is based on alternative sources, such as International Financial Reporting Standards (IFRS), a communication from the Czech National Bank or a recommendation from the Ministry of Finance. Given that each possible method of accounting entails certain imperfections, it is possible to expect an update of the legal regulations with the increasing use of cryptocurrencies.

\section{Data and Methods}

The objective of the paper is to evaluate the possibilities of the correct procedure for accounting for bitcoin according to valid accounting regulations. At the same time, shortcomings and risks in accounting and the overall impact on the outputs of the profit and loss statement and tax issues in reporting bitcoin will be identified, especially in the area of income taxes and VAT, both for legal and natural persons. The evaluation will be performed using model examples that focus on the use of bitcoin in business.

As a first option, the use of bitcoin as a means of payment will be used and it is charged in the context of goods or securities. The second variant of the model considers the extraction of bitcoin and is accounted for as a product. The third model example deals with bitcoin speculation, which is recorded in accounting as goods or other securities. A fourth model example is the evaluation of bitcoin billing when paying a wage or salary. As a first option, the use of bitcoin as a means of payment will be used and it is charged in the context of goods or securities.

For individual variants, income tax will be calculated according to valid regulations and any difference will be compared. 
Based on the synthesis of the obtained results of model examples, the reporting of bitcoin according to Czech accounting standards will be evaluated with subsequent recommendations for accounting entities and pointing out possible risks for reporting.

\subsection{Evaluation of model variants and Analysis of monitored variants}

The aim of the paper was to assess the possibilities of recording the cryptographic currency bitcoin in the accounting records and to evaluate possible risks and shortcomings in connection with the reporting of this currency, especially in relation to the issue of income taxes and VAT.

The main areas for the assessment area were selected as the monitored variants:

1. the use of bitcoin in companies, namely in the purchase and sale of business activities,

2. further in the "extraction" of bitcoins,

3. in investments and trading on the stock exchange,

4. in case of partial payment of wages.

Place the figure as close as possible after the point where it is first referenced in the text. If there is a large number of figures and tables it might be necessary to place some before their text citation.

\subsubsection{The use of bitcoin in companies, namely in the purchase and sale of business activities}

The classic model was chosen for purchase and sale based on the recommendation of the Ministry of Finance using the BitPay payment gateway, where bitcoin did not enter into accounting; The third option is the registration of bitcoin as a security (cash). The most advantageous option in this case is to use the BitPay payment gateway, which converts bitcoins into legal tender and does not enter into accounting. This suits customers who require new payment options and does not affect the entity's results of operations. When registering bitcoin on the Goods or Valuation accounts, the currency enters the accounting records and it is necessary to record bitcoin at the acquisition price, which includes fees for arranging this transaction by a bitcoin exchange office. When making payments in this way, the method has the character of a barter trade.

The problem is the valuation of bitcoin in Czech crowns. It is possible to recommend documenting the exchange rate of real prices from the Coin Market Cap server in dollars, here it is then possible to convert to the Czech koruna. However, it is necessary to consider the high volatility of the bitcoins, which must be recorded in the inventory. When using this option, it is more advantageous to keep bitcoins in inventory accounts, where it is possible to use provisions to reduce the decline in the value of the currency, which is, however, a non-tax deductible expense.

When bitcoins are registered as valuables, it is possible to create an exchange rate difference in the event of a decrease in value, which is tax effective and affects the economic result. Upon sale, it is necessary to issue an invoice in Czech currency, but the payment in bitcoins will no longer appear in the accounting. Here it is necessary to solve the administrative form of debt settlement, for example by a purchase contract or by using new platforms on the Internet.

At the end of the balance sheet date, the entity must make an inventory of the assets and assess whether the carrying amount of the assets is higher or lower than the market value. In the event that the book value is higher, in the case of bitcoins, due to compliance with the precautionary principle, it is necessary to make an adjustment in the form of a provision for inventories or short-term financial assets. In the case of bitcoins, it is not possible to 
proceed in the standard way, because the Czech National Bank does not consider bitcoin to be a currency, and therefore does not register an exchange rate list converted into the Czech koruna. To determine the most reliable conversion, you can use the average of the largest bitcoin exchanges or use data from CionMarketCapu.com, where prices are implemented from individual exchanges by a weighted average depending on the volume of transactions. Bitcoin is most often listed on stock exchanges in pairs with the US dollar, where conversion is already possible according to the CNB exchange rate list.

To determine income tax, the entity will follow the standard legal documents, namely the methodology for calculating corporate and personal income taxes. From the point of view of VAT registration, it is necessary to consider that all payments made by bitcoin are in the regime of liability for the payment of VAT by the recipient of the taxable supply.

\subsubsection{Further in the "extraction" of bitcoins}

Bitcoin mining should be classified as a continuous business activity; therefore, it is necessary to have a trade license and will be subject to income tax according to the standard classification of the entity. In this case, the appropriate option is to report bitcoin in the accounting records in the Products account. However, inaccuracies may arise when calculating the own costs of this activity (e.g. energy consumption, depreciation, other services, labor costs, etc.).

The extraction of one block cannot be characterized by regular intervals and it is not clear whether the wasted costs can be included in the calculation for the extracted block. In the product register, the costs of inefficient mining may be reported as scrap in the Deficit and Damages account, but in the case of bitcoin mining, the losses may be many times higher and the costs may exceed the profitability of one extracted block. It is therefore necessary to focus more on the purpose of mining and that is to find the block. Therefore, inefficient costs could fall into the final calculation.

The subject of income tax becomes extracted bitcoins together with the confirmation of transactions, their sale in a transfer to classic money or in exchange for other alternative cryptocurrencies, or goods or services. If the miner is a natural person who keeps tax records, then the mining itself will not be subject to tax, as only income and expenses are taxed. A lump sum of $60 \%$ of income can be claimed up to a turnover of CZK 2 million.

Bitcoin mining is accidental and therefore no exact link can be found between the service provided and the consideration received, therefore, according to the Court of Justice of the European Union, bitcoin mining should not be subject to VAT. However, a different situation arises in the case of an association of miners in a pool who provide their computing power for a fee. This is already about providing a service in the form of rental. In this situation, it is possible to claim input VAT on the deduction for the acquired property. However, the date the service is provided or the service received must be defined, which is usually the date the bitcoins are credited to the wallet.

With regard to the issue of bitcoin in connection with mining, it is appropriate to wait with the right to apply it to the decision and opinion of the relevant legislative authorities. The income tax of the association is determined for the miners who associate in the pool for each participant in the same way as for the mining itself.

\subsubsection{Investments and trading on the stock exchange}

For the model analysis of accounting for bitcoin as a speculative tool or a possible investment, two options were chosen by which the accounting unit recorded bitcoins either as financial assets or, as recommended by the Ministry of Finance, as inventories. Accounting as a financial asset is, due to the nature of the bitcoin, quite problematic with 
respect to the reporting of assets. Bitcoin is not actually a security, so when reporting on the accounts 069 -Other long-term financial assets or $257-O t h e r$ securities is not accurate. Nor is it possible to classify it as an intangible fixed asset because, from the point of view of the nature of the asset, it is highly liquid.

In the case of bitcoin records in the form of inventories, the valuation was determined by the acquisition price, which also includes other acquisition costs and the valuation of the removal of inventories by the FIFO method or the arithmetic average. Any adjustments are not tax deductible.

According to the comparison of both methods in the model example, it was stated that the balance sheet records will differ only by reporting bitcoins on other asset lines.

Trading in bitcoins on the stock exchange is divided into two variants depending on whether the entity handles only its own assets or not. Taxing this income can be problematic due to the fact that tens and hundreds of transfers are often used daily.

One of the biggest difficulties in reporting bitcoin in inventory accounts is its valuation at the balance sheet date, when there is no regulation that entities should follow when calculating the market price. Furthermore, the high risk of bitcoin volatility, which can cause high losses, needs to be considered. The model examples illustrated, when comparing values in profit and loss statements, how important it is to correctly value bitcoin in order to adhere to the principles of a true and fair view in accounting. It may be recommended that entities do not make bitcoin payments in excess of EUR 1000, as these payments may be considered risky.

European Court of Justice, VAT means that it will not be applied to stock exchange trading. Inventory or financial asset accounts can be used for accounting. However, bitcoin within financial assets cannot be revalued to fair value, but a provision can be created. Depending on the use of the account type, there is a difference in the calculation of the partial economic result, when the records as an inventory affect the operating VH, while the financial assets affect the financial $\mathrm{VH}$. As bitcoin acts more as a financial instrument for securing profits, it would be more relevant to include it in financial assets.

Trading in bitcoins is subject to income tax, which is calculated according to valid methodologies similarly to bitcoin mining. The risks of correctly determining the tax base lie in the very complex determination of the exact number of transactions, which often takes place on the basis of automated systems. Transfers from various cryptocurrencies to others are in this way undetectable to tax administrators until they are transferred to legal tender.

\subsubsection{Partial payment of wages}

With the possibility of paying wages in bitcoins, it is possible to use legal documents according to the Labor Code $\S 119$ on wages in kind. Entities record purchased bitcoins for the purpose of paying wages as inventories when accounting for method A and valuing at the time of removal from average value. By law, the minimum wage must be observed, the difference can then be paid in bitcoins.

Other amounts for social and health insurance contributions remain unchanged and there will be no reduction on the part of the employer. It is necessary to specify the deadline for determining the transfer of bitcoin to the employee's wallet, preferably in the employment contract.

From the employer's point of view, a wage in kind can be classified as a tax-deductible expense if the remaining part of the wage is also tax effective.

The bitcoin paid out is recognized in the income statement in the same way as for inventories. From a reporting perspective, this can cause bias in the increase in the value of inventories and the possible risk of losing its value. 


\section{Results and Discussion}

If the entity wants to use bitcoin in its business, it can be recommended to create appropriate analytical accounts or off-balance sheet records and thorough creation of internal guidelines that will declare the exact accounting procedure, and at the same time document the inventory from a virtual wallet or blockchain. When determining income tax, the procedure is in accordance with the Income Tax Act for both legal and natural persons. Taxation occurs not only when converting to the legal currency, but also when converting to another cryptocurrency, or when exchanging for goods or services.

The most problematic situation is when registering and using value added tax (VAT). According to the law, the subject of VAT is generally characterized by the supply of goods or services by a taxable person for consideration within the framework of carrying out an economic activity with a place of supply in the country, or the acquisition of goods from another Member State for consideration in the country. It follows that, in the case of the use of bitcoin as a means of payment, VAT will have no effect on the taxable transactions carried out. The only risk in this case is the liability for payment of VAT by the recipient. If an entity wishes to insure itself against unreliable payers, it can monitor the register of unreliable payers or resolve the situation by paying it directly to the relevant tax office, but this requires considerable administrative costs.

As part of the harmonization of VAT throughout the European Union, the first precedents have already been set in terms of bitcoin taxation. According to this case law, the Czech Republic is also governed and considers bitcoin in the framework of foreign exchange activities as a financial service exempt from VAT. The same goes for trading bitcoin on the stock exchange. The only possible application of VAT may be a miner in a pool where there is a direct link between the service provided and the payment received. In such a case, it is possible to consider the application of input VAT on the acquired property and other costs related to mining. However, due to the complexity of the case and no or inconsistent legal support, it is not recommended to charge VAT in connection with bitcoins.

Similar attitude holds the Federal Republic of Germany that interprets cryptocurrency as either the long-term intangible asset or other receivables. It evaluates cryptocurrencies by cost of acquisition defined similarly as in the Czech Republic. Different stand takes the Slovak Republic that integrates cryptocurrencies into the short-term financial assets and evaluates them by fair value. This stand differs also from interpretation of IAS/IFRS that include cryptocurrencies either in inventories or in the long-term intangible assets and recommend to evaluate them initially by cost of acquisition (Vodakova and Foltyn, 2020).

Generalization of practices, analysis of the best and most reliable models for assessing crypto assets can be a determining factor in choosing the accounting policy of the company, as well as determining further directions for improving their accounting and presentation of information in financial statements (Morozova et al., 2020).

The research by Allen et al. (2019) notes that a crypto asset can be an equity instrument, but only under the following condition: it must secure a contractual right to a residual interest in the net assets. From a practical point of view, when considering specific cryptoasset transactions, it is possible to identify some arguments in favour of classification as a financial instrument.

In choreographies, control over a process instance is shared between independent parties, and no party has full control or knowledge during process runtime. Nevertheless, it is necessary to monitor and verify process instances during runtime for purposes of documentation, accounting, or compensation (Prybila et al., 2020). 
By means of an empirical analysis through an online survey, the current operational dealing of incoming Bitcoin funds, the risk awareness of the potential threats, and the corresponding control activities implemented by companies accepting Bitcoin payments have been examined. The results reveal that the risks of this new technology-based payment method have not been extensively evaluated and that there exists a partially significant lack of know-how (Bölstler, 2019).

Blockchain technology has been a disruptive force in currency, supply chain, and information sharing practices across a variety of industries. Its usage has only recently expanded into assurance and financial reporting. Organizations utilizing blockchain must adapt their policies and procedures over internal controls and counterparty risk assessment to address increasing regulation over the distribution of financial data, while their audit committees must be prepared to address these challenges leading up to financial statement preparation (Smith and Castonguay, 2020).

According to the findings, bitcoin cannot be easily considered as money. The advantages of bitcoin, such as very quick payments worldwide, stop of inflations caused by governments trying to solve their own problems or high level of transactions privacy are widely mentioned (Kubat, 2015).

An instrument should be considered to be used within such a limited network if it can be used only either for the purchase of goods and services in a specific store or chain of stores, or for a limited range of goods or services, regardless of the geographical location of the point of sale. Clearly the European legislator was not thinking of peer-to-peer networks at that time, but rather about store cards, petrol cards, membership cards, public transport cards, meal vouchers or vouchers for services, but it could be argued that Bitcoin falls under that exemption because of its limited use ... for now. This would not make Bitcoin operate in a legal vacuum, but its exchanges would then be subject to the same regulations as for trading commodities or bartering (Jakobs, 2011).

Designed as a decentralised currency, Bitcoin is not intended to become a reporting currency and will instead complement fiat money. We argue that in the case of Bitcoin the accounting principle of faithful representation requires interpretation of the economic substance for financial reporting that varies with reporting entity: trading firms recognise Bitcoin like a foreign currency and measure the revenue, or expense, at the equivalent amount of the reporting currency and digital currency exchanges recognise Bitcoin as goods in line with tax accounting treatment (Tan and Low, 2017).

Solid cooperation among the international community, supported by unitary standards and procedures, will help boost the worlds AML/combatting the financing of terrorism (CFT) efforts. As an added bonus, effective regulation, monitoring and control can facilitate more efficient tax collection (Al-Tawil and Younies, 2021).

The discovered issues in the crypto-asset regulation in the UK may urge authorities to improve the existing regulatory frameworks and legal provisions (Huang, 2021). Before recommending cryptocurrency reporting itself, it is important to think about calculating the exchange rate. According to $\S 4$ paragraph 12 of Act No. 563/1991 Coll. Entities must be required to keep accounts in Czech currency. In the case of foreign currency, the exchange rates are converted at the exchange rate announced by the Czech National Bank. However, the Czech National Bank does not announce any exchange rate for cryptocurrencies. An appropriate solution may be to average the rates of cryptocurrencies against foreign ones at the time of valuation currency on two or three major stock exchanges or exchange offices. The average expressed in foreign currency calculated in this way is converted according to the exchange rate announced by the Czech National Bank into Czech crown (Kocourkova Trnkova, 2017). 


\section{Conclusion}

The text of IFRSs effective from 1 January 2018 does not there is no mention of cryptocurrencies. But that doesn't mean that IFRS would not be able to cope with new phenomena.

Unless the situation is explicitly regulated, the general procedure for choosing accounting methods. According to IAS 8.10, management must use the entity judgment in the choice and use of the accounting method the resulting information was reliable and relevant to economic decision-making of users of financial statements. In the in the absence of an explicit adjustment, the unit is limited to:

- the application of IFRS requirements that relate to transactions or events;

- considering the requirements of the Conceptual items and the criteria for their recognition and measurement (Prochazka and Roubickova, 2018).

At present, there are still no necessary guidelines to enable bitcoin to be accounted for uniformly, not even under the International Financial Reporting Standards (IFRS). Entities may then interpret the nature of bitcoin in different ways, leading to differences in profit or loss and the impossibility of comparability in reporting. The issue should be discussed and addressed in the framework of legislation and uniform approaches for accounting should be created, as bitcoin and other cryptocurrencies are still evolving and their popularity and use is still increasing. That issue is definitely indispensable and its impact is global in nature, so it is necessary to pay sufficient attention to the uniform approach in accounting.

\section{References}

1. Allen, D., Aselta, J., \& Engel, R. (2019). Cryptocurrencies for the Payment of Products or Services: Risks. Accounting Practices and Regulations. Accounting and Finance Research, 8(4), 19-34.

2. Al-Tawil, T.N., \& Younies, H. (2021). The implications of the Brexit from EU and bitcoin. Journal of Money Laundering Control, 24(1), 137-149.

3. Blazek, R., Durana, P., \& Valaskova, K. (2020). Creative Accounting as an Apparatus for Reporting Profits in Agribusiness. Journal of Risk and Financial Management, 13(11), 261.

4. Bölstler, M. (2019). The Influence of Cryptocurrencies on Enterprise Risk Management - an Empirical Evidence by the Example of Bitcoin. Junior Management Science, 4(2), 195-227.

5. Campbell-Verduyn, M. (2018). Bitcoin, crypto-coins, and global anti-money laundering governance. Crime Law Soc Change, 69, 283.

6. Dierksmeier, C., \& Seele, P. (2018). Cryptocurrencies and Business Ethics. J Bus Ethics, 152, 1-14.

7. Huang, S.S. (2021). Crypto assets regulation in the UK: an assessment of the regulatory effectiveness and consistency. Journal of Financial Regulation and Compliance, 29(3), 336-351.

8. Jacobs, E. (2011) Bitcoin: A Bit Too Far? Journal of Internet Banking and Commerce, $16(2)$.

9. Kocourkova Trnkova, H. (2017). Daňové a účetní aspekty kryptoměn. 1YouTube.com [online].

10. Kubat, M. (2015). Virtual Currency Bitcoin in the Scope of Money Definition and Store of Value, Procedia Economics and Finance, 30, 409-416. 
11. Morozova, T., Akhmadeev, R., Lehoux L., YumashevA., Meshkova, G., \& Lukiyanova, M. (2020). Crypto asset assessment models in financial reporting content typologies. Entrepreneurship and sustainability issues, 7(3).

12. Niranjanamurthy, M., Nithya, B.N. \& Jagannatha, S. (2019). Analysis of Blockchain technology: pros, cons and SWOT. Cluster Comput, 22, 14743-14757.

13. Prochazka, D., \& Roubickova, J. (2018). Jak na Bitcoin podle IFRS, AUDITOR 8, 713.

14. Prybila, Ch., Schultea, S., Hochreinera, Ch., \& Weberb,I. (2020) Runtime verification for business processes utilizing the Bitcoin blockchain. Future Generation Computer System, 107, 816-831.

15. Smith, S.S., \& Castonguay, J. (2020). Blockchain and Accounting Governance: Emerging Issues and Considerations for Accounting and Assurance Professionals, Journal of Emerging Technologies in Accounting, 17(1), 119-131.

16. Stroukal, D., \& Skalicky, J. (2018). Bitcoin a jiné kryptopeníze budoucnosti: historie, ekonomie a technologie kryptoměn, stručná přiručka pro úplné začátečníky. Grada Publishing.

17. Tan, B.S., \& Low, K.Y. (2017). Bitcoin - Its Economics for Financial Reporting. Australian Accounting, 27(2),115-228.

18. Usnesení Evropského parlamentu ze dne 26. května 2016 o virtuálních měnách (2016/2007(INI)) (European Parliament, 2016)

19. Valaskova, K., Kliestik, T., Svabova, L., \& Adamko, P. (2018). Financial Risk Measurement and Prediction Modelling for Sustainable Development of Business Entities Using Regression Analysis. Sustainability, 10(7), 2144.

20. Vodakova, J., \& Foltyn, J. (2020). Valuation of Cryptocurrencies in Selected EU Countries. 35th International-Business-Information-Management-Association Conference (IBIMA)Education excellence and innovation management: a 2025 vision to sustain economic development during global challenges, (pp.15529-15534). 